\title{
Interactive Learning Management System to develop Spatial Visualization Abilities
}

\author{
Carlos Melgosa Pedrosa, Basilio Ramos Barbero, M. Esther Baños García \\ Graphic Expresion Department, Escuela Politécnica Superior, Universidad de \\ Burgos, Avda. Cantabria s/n. 09006 Burgos, Spain.
}

\begin{abstract}
An Interactive Learning Management System (ILMS) is presented, which functions as a webbased Spatial Visualization Ability (SVA) learning support tool for students of engineering graphics and as a management tool for teachers to track student learning. This software is designed to fill the gaps in student knowledge, giving them more uniform spatial visualization abilities when enrolling on University Engineering degrees.

The ILMS_SVA consists of: 1) a Content Management System (CMS); 2) a preliminary level assessment test; 3) a web-based tool for exercise management and self-assessment incorporating a $3 \mathrm{D}$ viewer that functions as an interactive tutorial (IT), allowing the manipulation of 3D objects in every exercise; 4) a database.

It is designed for three types of users (student, teacher and administrator), and has been validated with engineering graphics students at the University of Burgos (Spain) by means of experimental trials in the classroom and a user satisfaction survey, over two academic years. The results indicate that use of this tool improved SVA among students generally and was even of greater effectiveness for those students that accessed engineering courses with no prior knowledge of Technical Drawing.
\end{abstract}

Keywords: Learning Management System (LMS), Web3D, Virtual interactive learning, Interactive Tutorial (IT), Spatial ability.

\section{INTRODUCTION}

SVA is the most critical component of graphic representational skills for a substantial number of researchers [1] [2] [3]. Accordingly, SVA represents a key component for students enrolling on industrial engineering courses with very poor SVA skills that have critical consequences for their subsequent performance. In consequence, we have to deal with heterogeneous groups of students on these courses, which makes the teaching-learning process and the retention of a significant numbers of students, more difficult.

According to Saorín [4] and Martín-Gutiérrez [5], SVA is understood as the ability to manipulate objects and their parts mentally in space. SVA is one of the components of human intelligence that implies integrating aptitudes, skills and dexterities.

Studies conducted by Duff [6], Brus [7] and Knott [8] have demonstrated that between 13\% and $17 \%$ of students enrolled on technical courses experience difficulties with SVA (students that do not achieve over $60 \%$ in the PSVT-R test [9]). In Spain, technical drawing is an optional subject in secondary education. Our research indicates that approximately $37 \%$ of students studying industrial engineering at Burgos University enroll with no prior knowledge of technical drawing.

In this regard, Scribner [10] recommended that teachers should include tools to improve the learning techniques of their students in the development of SVA, such as: sketches, real 
models that they can touch, solid models with CAD programs, isometric and orthogonal projections.

Hence, SVA needs to be developed and improved by means of progressively more difficult exercises for students, which facilitate their understanding of the mechanisms that control the 2D-3D relationship, by using asynchronous tools adapted to the pace of learning of each student.

\section{Literature}

As Harper [11] pointed out, apart from reality, the most appropriate way to generate an authentic learner-based activity may be through the use of EVEs (Educational Virtual Environments). Constructivism is the fundamental theory that motivates the educational use of EVEs. According to this theory, student interaction is a relevant part of the learning process and Web3D technologies contribute immense interaction and flexibility. Research into techniques and educational systems associated with the use of Web3D programs is very limited and holds great potential for a wide number of educational applications that require visual comprehension $[\mathbf{1 1}, \mathbf{1 2}$. Along these lines, Violante [13] argued, on the basis of her findings, when visualizing and interacting with $3 \mathrm{D}$ objects, that Web3D technologies are effective in the fields of engineering. However, as Chittaro [14] stated, we should not overlook some of the limitations of Web3D technologies in the use of EVEs. These are as follows: lack of experience and interest towards their use by teachers; browsers that are not always very intuitive, user friendly, and low cost; and the absence of a standard evaluation method for Web3D technologies (with the consequence that their contributions may not always be relevant).

The following studies (some with contradictory results) on the effectiveness of the various methodologies that employ EVEs for the development of SVA, fundamentally CAD and multimedia applications, may be highlighted:

- Sorby [15], made it clear that the completion of exercises (where appropriate using IDEAS software) improved the learning processes of students with greater learning difficulties.

- Rafi [16] found significative evidence that the use of Web3D applications as well as 3D pedagogic tools in VRML format improved the development of spatial skills.

- Koch [17] demonstrated that there were no significant differences between sketching and solid-modeling design methods used to find solutions to technical problems $(\mathrm{p}=.752)$.

- Konukseven [18] compared traditional methods on an Engineering Graphics course with a teaching method that depended on 3D models in VRML format. The results showed that both methods were of the same quality.

- Martín-Gutiérrez [5] verified that the combined use of a multimedia application with simultaneous 3D manipulation of the objects and its main projection planes, improved SVA levels in geometry.

- Pando [19] concluded that the use of interactive tools in the teaching of Engineering Drawing significantly improved the results of traditional learning in this subject.

E-learning platforms, as Simões [20] reaffirmed, present new ways of sharing and disseminating learning content and of monitoring student progress, through the use of intelligent systems, and the simulation of virtual classroom environments, which facilitate asynchronous learning in EVEs. These platforms represent a major influence in the work of 
both students and teachers. However, the components of many existing e-learning platforms have failed in terms of their simplicity. In addition, there is a growing need for users to have access to a platform that incorporates new features in a transparent and simple way. In this context, LMS are computer programs that integrate functions for teaching, evaluation, and course management. The use of LMS in engineering education can improve student follow-up for the tutor and the student's own review of personal progress.

Consequently, we have focused our efforts on the design of a tool that would autonomously enhance the SVA of students, adapting to their initial level, while providing feedback on their learning process. At the same time, it would automatically assess student progress in terms of the knowledge that they have gained.

\section{Aims of the present study}

From a conceptual point of view, our main objective was to integrate the $3 \mathrm{D}$ virtual models into the different self-evaluation exercises proposed for students in the LMS. In the search for solutions to different exercises, virtual interaction with the $3 \mathrm{D}$ models and their on-screen manipulation should be possible, to help student solve the various set exercises, and in doing so, to assist the development of their SVA. A free 3D viewer is therefore needed that can download 3D models from the Web.

Our other objectives at this stage of the design were as follows:

- The LMS should be freely available on the web and should have the capacity to receive and to send information through a database, in such a way that relevant information may be stored, searched for, organized and retrieved in an efficient manner. Most Content Management Systems (CMS) meet these objectives.

- It should offer different levels of access, so that our students can complete different exercises at random or as proposed by the teachers, in accordance with their prior knowledge of the subject matter, for which reason a pretest in the LMS will be necessary to ascertain the knowledge level of each student.

\section{Decisions}

We initially proposed an educational WebCT or Moodle type platform to manage an Interactive Tutorial (IT) program for use as a management and evaluation tool and to track student learning.

The integration of virtual 3D models with 3D viewers, the IT and the other elements in the Moodle platform of our university has proved to be an elusive goal. In consequence, we considered that it would be better, for our purposes, to integrate the use of $3 \mathrm{D}$ virtual models through $3 \mathrm{D}$ viewers using a CMS with a customized database. EDrawings is the free $3 \mathrm{D}$ viewer used.

An Interactive Learning Management System to develop Spatial Visualization Abilities (ILMS SVA) was therefore designed by assembling: 1) a CMS; 2) a preliminary level assessment test; 3) a web-based tool for exercise management and self-evaluation; 4) a database that is designed for three types of users: student, teacher and administrator.

We designed a 55-item survey to confirm whether this is a valid and useful tool for managing the learning of SVA by using interactive 3D models on the computer. 
The ILMS_SVA was also used in the classroom, measuring its effectiveness by means of a comparison with the traditional method.

\section{BACKGROUND TO WEB-BASED SPATIAL VISUALIZATION LEARNING TOOLS}

At present, a number of web-based applications may be found that are either partly or wholly centered on the development of SVA.

The methodological process to analyze these applications was as follows:

$1^{\circ}$ As explained in the 'Introduction', we took the three basic characteristics that these tools should fulfill as our starting point: a) aim to develop SVA, b) offer free, easy and rapid access, and c) appear in multimedia format, to facilitate the autonomous learning of students.

$2^{\circ}$ With these baseline criteria, internet searches with different search engines were performed on a wide range of academic journals, conference proceedings and web-based applications. As a result and bearing in mind additional studies by Melgosa et al. [21], Jorge Martin et al. [22], and Martin G. [23], we selected 22 applications that we studied in depth to identify common and uncommon features from among them all.

$3^{\circ}$ In this analysis, we identified 5 further characteristics, which were collected and evaluated in these studies, that should be added to the three basic characteristics that have already been confirmed, which resulted in the list of 8 fundamental requirements:

- VISKILL: the development of 3D visual skills as the priority objective.

- 2DAT: text and animations in two dimensions in FLASH, JAVA, Director, etc.

- 3DO: manipulable 3D objects.

- VIDEO: videos.

- EXER: calculation and display of the results and qualifications of the completed exercises.

- TMLDB: transmission and tracking of learning by means of a database connection.

- FACC: open access and easily located.

- VoC: validated or used in a comparative study.

A comparison of all the characteristics of these applications is shown in Table 1, in which we brought together the 18 more representative applications studied. In this table, we can see that all applications have text and 2D animation; not all of the applications have 3D manipulable objects that provide 3D interactivity; only three include data transmission and tracking of learning achievements on a database; and, finally, not all of them are openly accessible with efficient SEO (Search Engine Optimization) tools.

Our aim in designing the ILMS_SVA was to meet the eight requirements listed above, since none of the 18 tools that are evaluated in table 1 meet them all.

The program, specified in row 8 of table 1, forms part of our previous research [24] into the design of web-based tools for the learning of spatial visualization. It is easily seen that one of the requirements (TMLBD) is not present in this interactive tutorial. Contero [25] employed this interactive tutorial, in 2005, in one of his three study groups, and demonstrated, at a significance level of $95 \%$, that students using our interactive tutorial managed to improve their spatial visualization skills. 
Table 1. Web tools and their compliance with requirements

\begin{tabular}{|c|c|c|c|c|c|c|c|c|c|}
\hline $\mathbf{N}^{\circ}$ & Name \| URL & 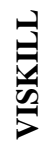 & 荇 & 㝕 & 号 & $\underset{\substack{x \\
x}}{x}$ & $\sum_{i}^{\infty}$ & 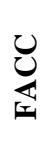 & $\stackrel{0}{j}$ \\
\hline 1 & $\begin{array}{l}\text { 2D Mental Rotation (University of Wisconsin, Milwaukee) } \\
\text { || https://pantherfile.uwm.edu/johnchay }\end{array}$ & $\mathbf{X}$ & $\mathbf{X}$ & & & $\mathbf{X}$ & & $\mathbf{X}$ & $\mathbf{X}$ \\
\hline 2 & $\begin{array}{l}\text { VIZ Visualization Assessment and Training (Pennsylvania State } \\
\text { University) || http://viz.bd.psu.edu/viz }\end{array}$ & $\mathbf{X}$ & $\mathbf{X}$ & & $\mathbf{X}$ & $\mathbf{X}$ & $*$ & $\mathbf{X}$ & $X[26]$ \\
\hline 3 & $\begin{array}{l}\text { Engineering Graphics Games and Quizzes (University of Texas) } \\
\text { || http://crown.panam.edu/EG/games/index.htm }\end{array}$ & $\mathbf{X}$ & $\mathbf{X}$ & & $\mathbf{X}$ & $\mathbf{X}$ & & $\mathbf{X}$ & $\mathbf{X}[27]$ \\
\hline 4 & $\begin{array}{l}\text { Isometric Drawing Tool (National Council of Teachers of } \\
\text { Mathematics) } \\
\| \text { http://illuminations.nctm.org/ActivityDetail.aspx?ID }=125\end{array}$ & $*$ & $\mathbf{X}$ & $\mathbf{X}$ & & & & $\mathbf{X}$ & $X[28]$ \\
\hline 5 & $\begin{array}{l}\text { Multiview Drawing (Conolly Maicher) } \\
\| \text { http://kellenmaicher.com/portfolio/projects/multiview.html }\end{array}$ & & $\mathbf{X}$ & & & $\mathbf{X}$ & & & $X[29]$ \\
\hline 6 & $\begin{array}{l}\text { Mental Rotation Training (Björn Kechel) } \\
\text { || http://bjornson.inhb.de/?p }=55\end{array}$ & $\mathbf{X}$ & $\mathbf{X}$ & & & $\mathbf{X}$ & $*$ & $\mathbf{X}$ & $*$ \\
\hline 7 & $\begin{array}{l}\text { CubeTest (Jos van den Oever) } \\
\text { || http://www.vandenoever.info/software/cubetest }\end{array}$ & $\mathbf{X}$ & $\mathbf{X}$ & $\mathbf{X}$ & & $\mathbf{X}$ & & $\mathbf{X}$ & \\
\hline 8 & $\begin{array}{l}\text { Innovative learning for the visualization of parts in a virtual } \\
\text { workshop (Burgos University, Spain) } \\
\text { || http://www2.ubu.es/expgraf/expgrain/visualizacion3d }\end{array}$ & $\mathbf{X}$ & $\mathbf{X}$ & $\mathbf{X}$ & $\mathbf{X}$ & $\mathbf{X}$ & & $\mathbf{X}$ & $\mathrm{X}[25]$ \\
\hline 9 & $\begin{array}{l}\text { Building with Blocks (Freudenthal Institute for Science and } \\
\text { Mathematics Education) } \| \text { http://www.fisme.science.uu.nl/ } \\
\text { toepassingen/00339/ toepassing_wisweb.en.html }\end{array}$ & $\mathbf{X}$ & $\mathbf{X}$ & $\mathbf{X}$ & & $\mathbf{X}$ & & $\mathbf{X}$ & $\mathrm{X}[30]$ \\
\hline 10 & $\begin{array}{l}\text { Web-based Virtual Environment (WbVE); Universiti Pendidikan } \\
\text { Sultan Idris (UPSI). Malaysia } \\
\text { || http://www.upsi.edu.my/ kanuar/luk.htm }\end{array}$ & $*$ & $\mathbf{X}$ & $\mathbf{X}$ & & $\mathbf{X}$ & & & $X[16]$ \\
\hline 11 & $\begin{array}{l}\text { 3D Interactive Model Web (3DIMW); National Kaohsiung Normal } \\
\text { University (Taiwan) } \| \text { http://140.127.45.25/3d/index.aspx?lang=en }\end{array}$ & & $\mathbf{X}$ & $\mathbf{X}$ & $\mathbf{X}$ & $*$ & $\mathbf{X}$ & $*$ & $\mathbf{X}[31]$ \\
\hline 12 & $\begin{array}{l}\text { Interactive Tutorial for Spatial Intelligence (Limerick university, } \\
\text { Ireland) || http://www3.ul.ie/tilde_accs/mearsa/www/9519211 }\end{array}$ & $\mathbf{X}$ & $\mathbf{X}$ & $\mathbf{X}$ & & $\mathbf{X}$ & & $\mathbf{X}$ & \\
\hline 13 & $\begin{array}{l}\text { Normalization (Instituto de Tecnologías Educativas Ministry of } \\
\text { Education and Science, Spain) } \| \text { http://ntic.educacion.es/w3//recursos } \\
\text { /bachillerato/dibujo/tecnico/normalizacion/index.htm }\end{array}$ & $*$ & $\mathbf{X}$ & $\mathbf{X}$ & & & $\mathbf{X}$ & $\mathbf{X}$ & $\mathbf{X}[32]$ \\
\hline 14 & $\begin{array}{l}\text { Virtual lab. for the study of the dihedral system (Instituto de } \\
\text { Tecnologías Educativas - Ministry of Education and Science, Spain) } \\
\text { || http://ntic.educacion.es/w3//eos/MaterialesEducativos/mem2008 } \\
\text { /laboratorio_virtual sistema diedrico/index.html }\end{array}$ & $*$ & $\mathbf{X}$ & $\mathbf{X}$ & & & $\mathbf{X}$ & $\mathbf{X}$ & $\mathbf{X}[32]$ \\
\hline 15 & $\begin{array}{l}\text { Children's games: matching games, tangrams... \| } \\
\bullet \text { http://www.primarygames.com/puzzles/match_games.php } \\
\bullet \text { http://www.juegosfan.com/tangram } \\
\bullet \text { •http://pbskids.org/cyberchase/math-games/tanagram-game }\end{array}$ & $\mathbf{X}$ & $\mathbf{X}$ & & & & & $\mathbf{X}$ & $*[33]$ \\
\hline 16 & $\begin{array}{l}\text { Wolfram Demonstrations Project || } \\
\text { •http://demonstrations.wolfram.com/SimpleSpaceVisualizationTest } \\
\bullet \text { http://demonstrations.wolfram.com/SimpleSpaceVisualizationTest2 } \\
\text { •http://demonstrations.wolfram.com/AdvancedSpaceVisualizationTest } \\
\text { •http://demonstrations.wolfram.com/MazesOnPolyhedra } \\
\bullet \text { http://demonstrations.wolfram.com/TestYourSpatialVisualizationAbilities } \\
\text { •http://demonstrations.wolfram.com/PolyhedraPerspectiveProblems }\end{array}$ & $\mathbf{X}$ & $\mathbf{X}$ & $\mathbf{X}$ & & $\mathbf{X}$ & & $\mathbf{X}$ & \\
\hline 17 & Fibonicci || http://www.fibonicci.com/spatial-reasoning & $\mathbf{X}$ & $\mathbf{X}$ & & & $\mathbf{X}$ & & $\mathbf{X}$ & \\
\hline 18 & $\begin{array}{l}\text { Queendom, the land of tests || http://www.queendom.com/tests } \\
\text { /access_page/index.htm?idRegTest }=1118 \# \text { n }\end{array}$ & $\mathbf{X}$ & $\mathbf{X}$ & & & $X$ & $\mathbf{X}$ & $\mathbf{X}$ & $\mathbf{X}$ \\
\hline
\end{tabular}




\section{METHODOLOGY}

We used the methodology proposed by Pérez [34], which is divided into 6 levels, for the development of the interactive tutorial to improve SVA:

- Level 1: Identification or recognition. The correspondence between the surfaces of the isometric projection of a model and its projections in the normalized views are identified, and vice-versa. To do so, a prior understanding of the concepts of cylindrical projection and the theory of how to obtain normalized views (front, top and side) is necessary.

- Level 2: Comprehension. The student assimilates the edges and faces of the normalized views that correspond to the given perspectives of the models.

- Level 3: Application. In a first phase, identification-discrimination criteria are applied, which help the student develop and rotate the model, in order to manipulate the object mentally in space. In a second phase, 3D object rotation exercises are proposed.

- Level 4: Analysis. In a first phase, the student should relate, evaluate, deduce and count the prismatic elements that are in contact with a specific prism, within a volume formed by stacking equal-sized prisms. In a second phase, the student obtains the views from the given perspectives.

- Level 5: Synthesis. Obtaining the perspective of the object from its views.

- Level 6: Evaluation. Where two of the views of the object are given and a third view is requested.

The effectiveness of spatial vision training using this methodology was validated with significative results by Pérez [34] who stated that, the number of students whose results were above a pre-set average mark after training rose from $47.4 \%$ to $72.6 \%$.

We included the first four levels mentioned above in the visualization tutorial, completing the fifth and sixth levels in the classroom without the tutorial. This methodology falls within an intermediate classification of spatial visualization parameters, somewhere among: a) the 3 components (spatial relations, spatial manipulation and visual penetrative ability) proposed by Titus [35], b) the 9 components (isometric sketching; orthographic projection - normal surfaces; flat patterns; rotation of objects about a single axis; rotation of objects about two or more axes; object reflections and symmetry; cutting planes and cross sections; surfaces and solids of revolution; combining solids) proposed by Sorby [36], Ault [37] and Veurink [38], c) and the 10 components proposed by Veurink [39], who adds the nine components prior to orthographic projection - inclined and single curved surfaces.

The use of a CMS with a database of exercises and the use of 3D viewers, linked to the methodology proposed in the interactive tutorial, assists and trains all students in the development of SVA and principally those who have greater difficulties with spatial visualization, as the combination of the three elements leads to four important complements, which are:

1- The possibility of manipulating the $3 \mathrm{D}$ model on the computer, as a tool to assist students with those exercises that they find most difficult: visualization and mental rotations in the space of the model. This is to help understand the cognitive process of spatial rotation.

2- The possibility of completing pre-tests that identify the level at which the students experience difficulties with spatial visualization, thereby recommending a starting level for the student in the IT. 
3- Asynchronous learning, at the student's own pace, with instant access to self-evaluation records.

4- Automatic tracking of student learning for the teacher.

\section{STRUCTURE AND DESIGN}

Continuous assessment and tracking of the learning achievements of our university students, in keeping with of the EHEA (European Higher Education Area) criteria proposed at Bologna, are key elements for their assessment. This justifies the need to design an IT with a system to manage both content and student learning, which can track: Who? When? How Many? How? -following either an order, or the proposed levels, or at random- Where our students entered? -and finally- What are their learning achievements?

Supported by the methodology used in the virtual tutorial (preceding section), we designed the ILMS_SVA with access to a database serving three types of users: 1) student, 2) administrator and 3) teacher (Fig. 1).

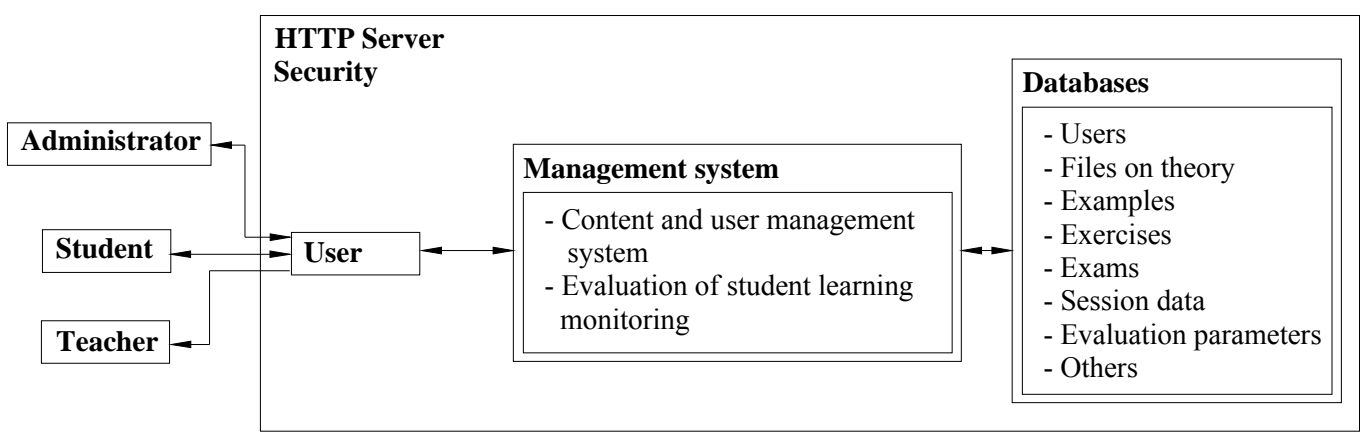

Fig.1. Overall structure of the ILMS_SVA

The descriptions of the three types of users are:

- Student User. The student accesses the ILMS_SVA at the following URL: http://www2.ubu.es/calcubu/

Students who enter the ILMS_SVA for the first time should:

- Complete a preliminary level assessment test that will recommend a starting level for students, even though they can always choose to ignore the suggestion and start at any of the available levels. See figure 2 showing the process of recommendation of starting level.

- Select the recommended level. The ILMS_SVA automatically creates a set of exercises at the level chosen by the students and at higher levels. The proposed exercises are selected at random from among those available at each level in the database.

- When running the ILMS, students can: consult theory; complete guided examples without storing their grades on the database and with the possibility of watching an explanatory video; create a new set of exercises with random inputs from the level that is selected and subsequent levels; complete unfinished exercises in a set of exercises, or repeat those with unsatisfactory results; and review their progress. 


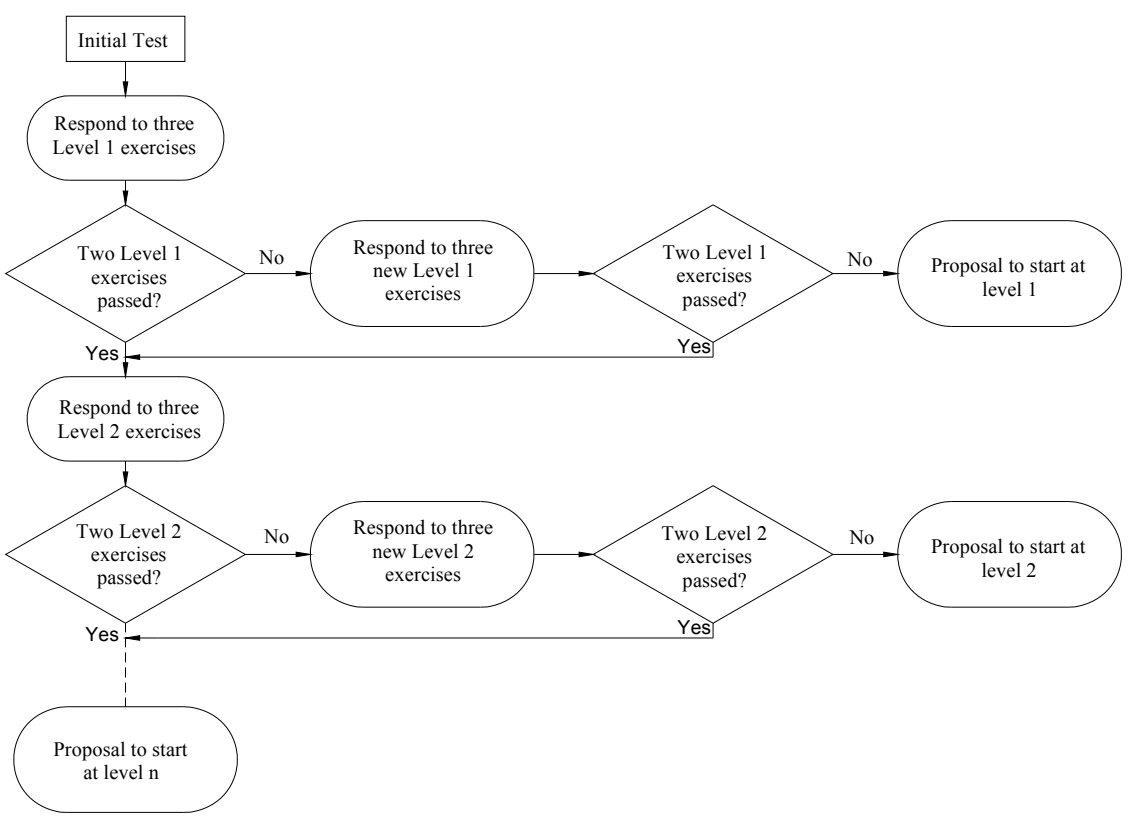

Fig. 2. Test to recommend the starting level in the ILMS

Each time students open a session they can see: the results of their exercises and/or exams (Fig. 3 ), whether these are finished; they can also review the finished exercises among the set exercises and exams, those that need to be finished, correct answers and mistakes; the information on dates, duration, grades and access numbers may be consulted by the student at any point in time.

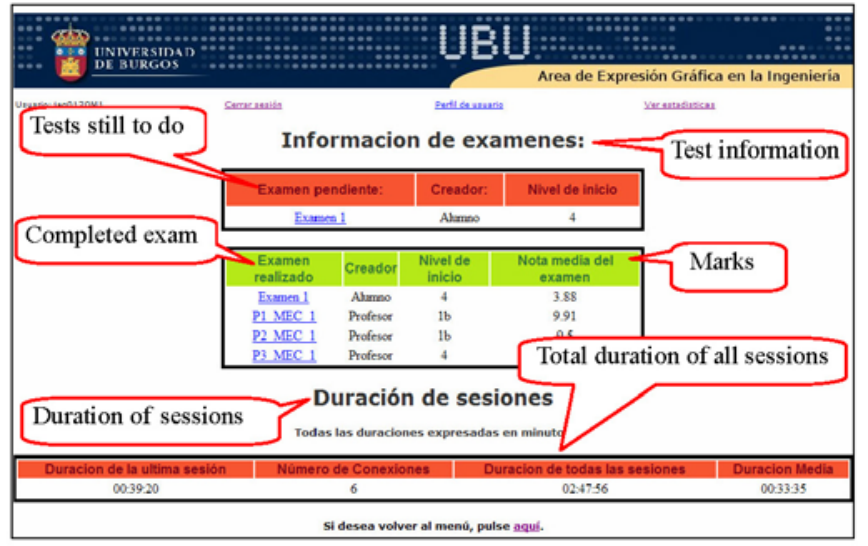

Fig. 3. Assessment of the exercises/exams that may be viewed by the student and the teacher

- Administrator User. It includes typical management functions such as creating and deleting users and groups, creating examples, set of exercises and exams, etc.

- Teacher User.

The principal function of teachers in the ILMS_SVA is continuous evaluation and tracking of student learning, for which purpose a series of statistics menus are available to them: viewing a student's results and statistics (Fig 3), viewing the statistics of sets of exercises/exams completed by a group of students, viewing statistics by exercises and levels (Fig 4).

The statistics that are automatically generated for each of the exercises at each level (Fig. 4) provide us with very important information, as they allow us to establish the difficulty of each exercise in comparison with the other exercises at that level and whether the distracters in each exercise are sufficiently discriminatory or whether they need further modification. 


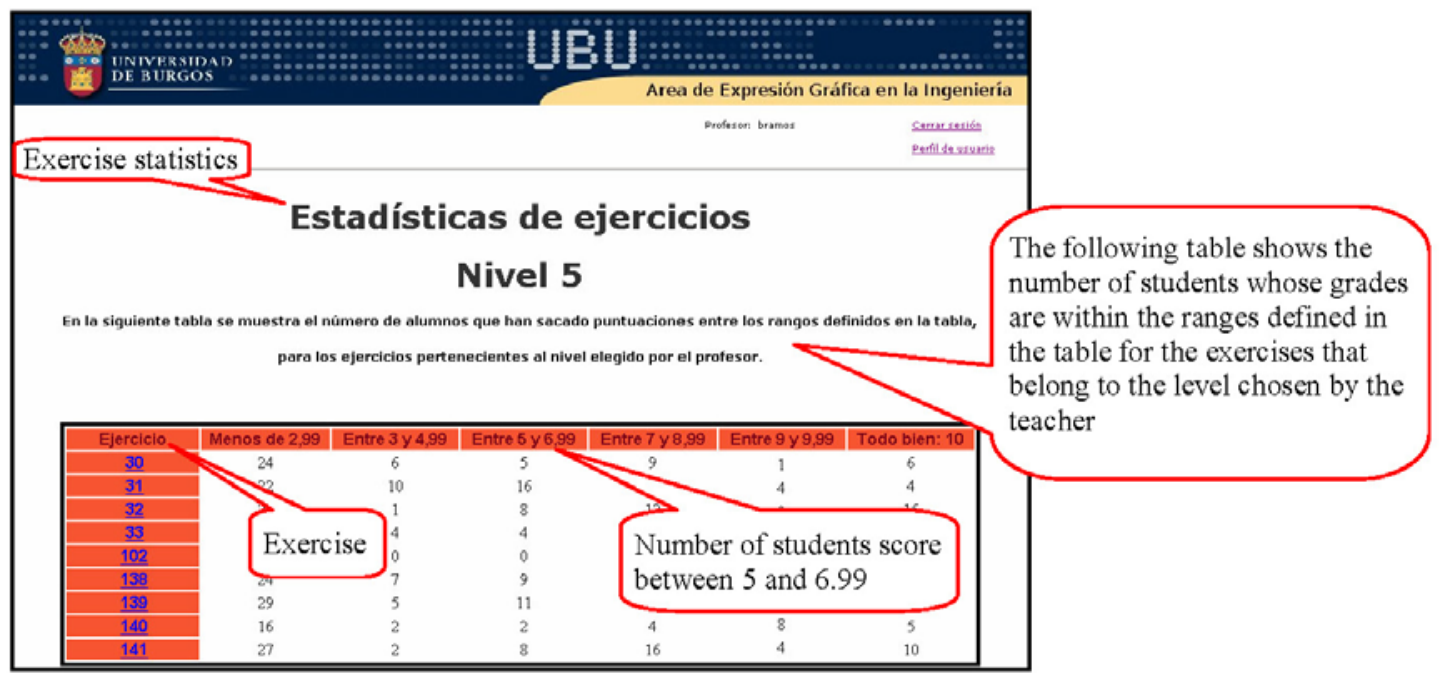

Fig. 4. Statistics of exercises for every level

The teacher's second function concerns the preparation of documentation, creating *.doc, *.pdf, *.jpg, *.avi, *.mov, *.eprt and *.easm type files, that the administrator can input into the database.

\section{Design of the ILMS_SVA taking into consideration different learning levels}

Level 1: Identification. Recognition of normalized surface views in the perspective view (Fig. 5) and vice-versa.

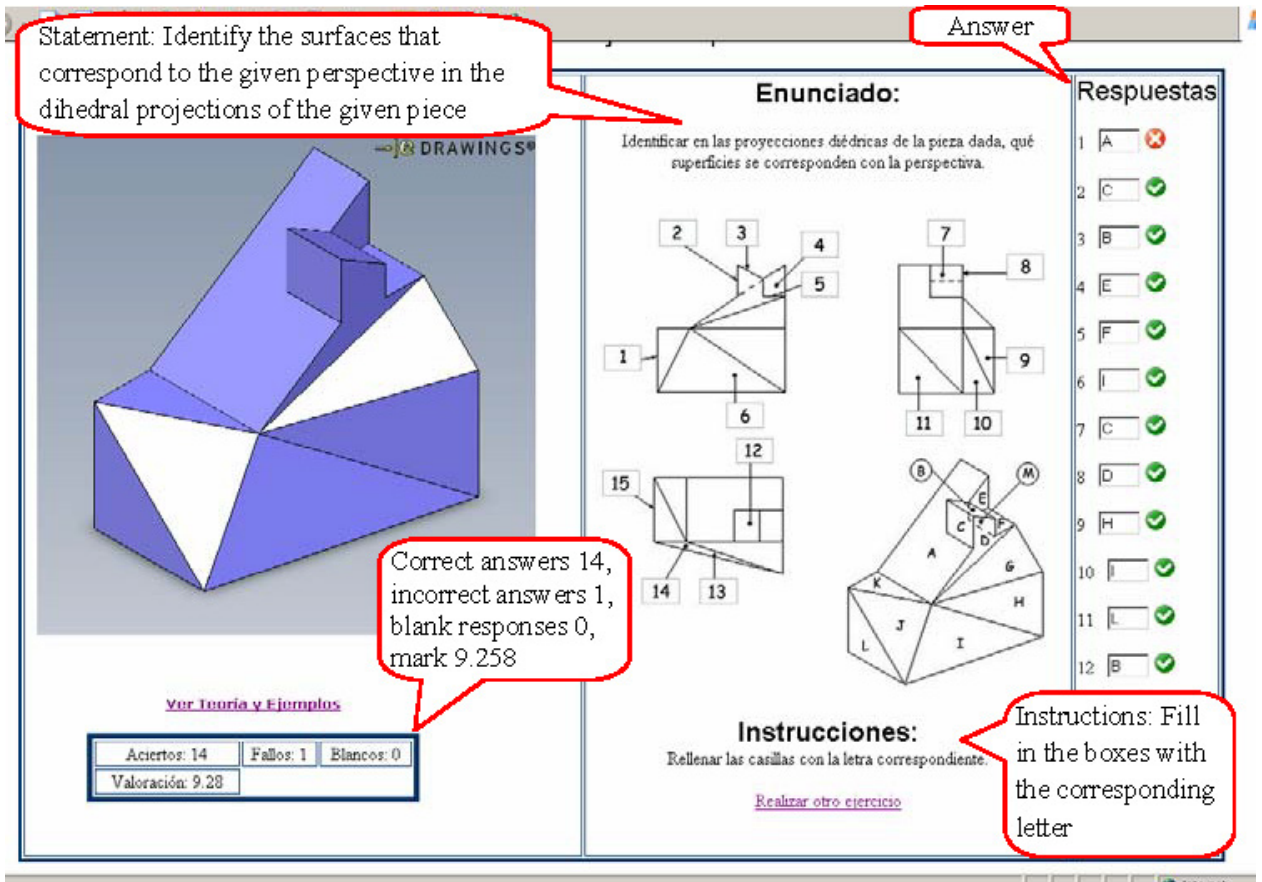

Fig. 5. Identification of the surfaces in standard views

The 3D model in the eDrawings file (to the left of the screen) may be manipulated in each exercise, using the buttons of the mouse to zoom in, rotate and frame (Fig. 5). This manipulation assists students with mental visualization and rotation of the models, as they can observe these movements beforehand on the computer. 
After pressing the button "Ver Resultados" [See Results] (Fig. 6), the system displays: the correct answers $\mathcal{O}$, the incorrect answers 2 , the number of correct, incorrect and blank responses, and finally the total mark (Fig. 5).

Level 2: Comprehension. Involves identifying which of the given views exactly correspond to some of the normalized views (front, top and side) of the model in the perspective view. (Fig. 6).

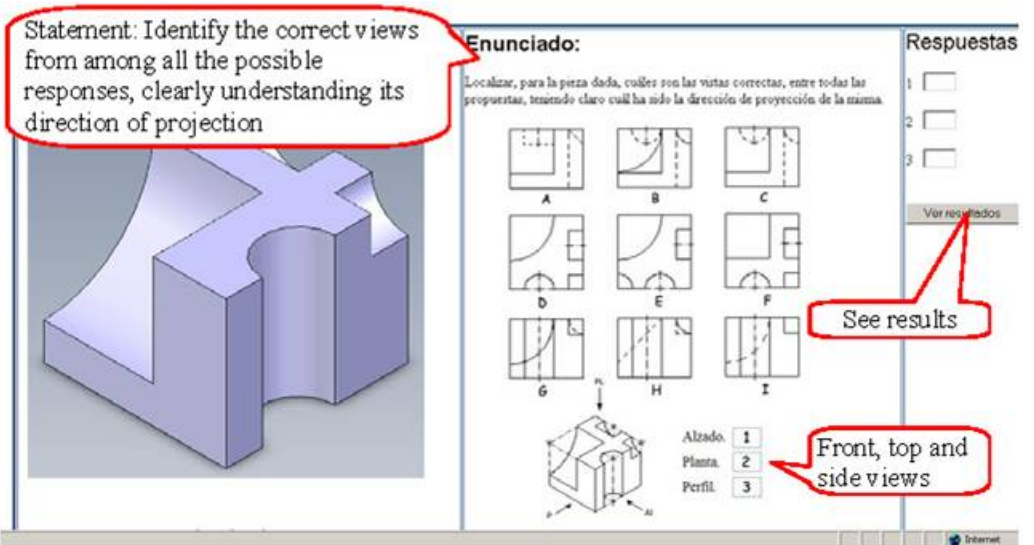

Fig. 6. Comprehension

Level 3: Application. This level is divided into three types of exercises: two of which are based on the developed (unfolded) models that require understanding of the rotation of a face, maintaining the other faces fixed at each step (Fig. 7); and the third type of exercise, which considers a complete rotation of the object around the $\mathrm{x}, \mathrm{y}$, and $\mathrm{z}$ axes with values of $90^{\circ}, 180^{\circ}$ and $270^{\circ}$, maintaining a fixed perspective (Fig. 8).

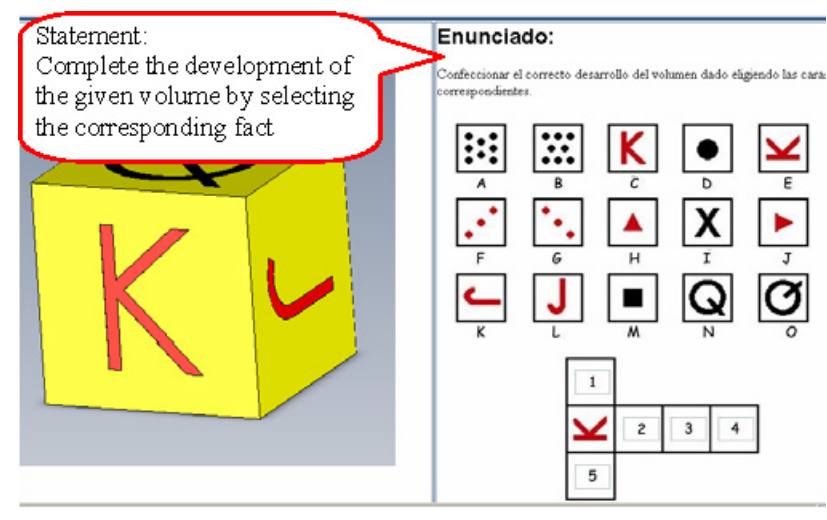

Fig. 7. Development of the cube
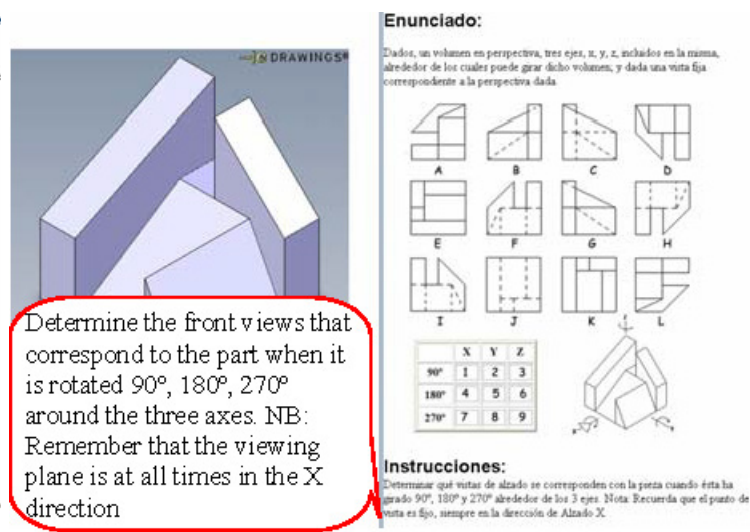

Fig. 8. Object Rotations

Level 4: Analysis. There are two modalities. In the first, the prisms in contact with the different prisms, A, B, $\ldots$, labeled in figure 9, have to be identified and counted. In the second modality, an analysis has to be made of which of the given views correspond to some of the possible perspective views of the part

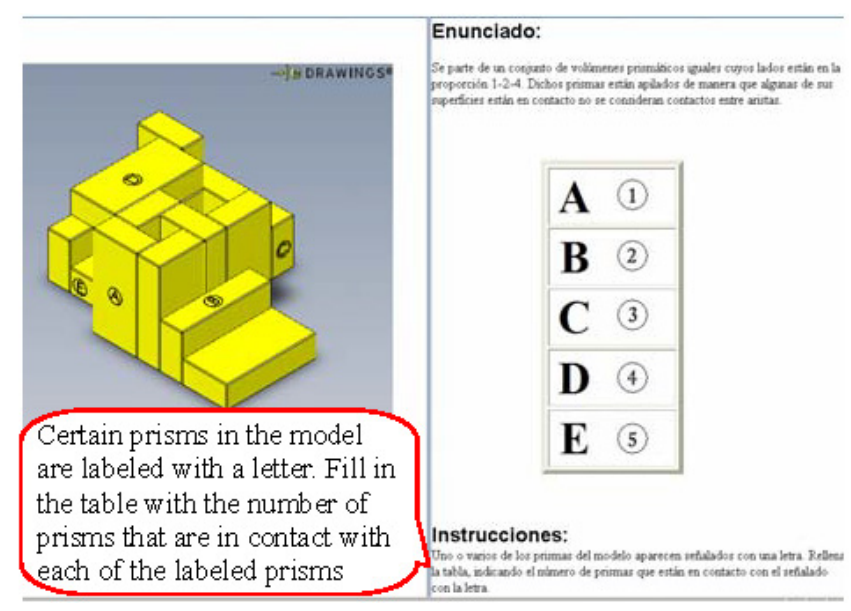

Fig. 9. Analysis of the prisms in contact 


\section{VALIDATION}

Two small groups of students (17) and teachers participated in the fine-tuning of the application. Subsequently, over the two academic years 2009-2010 and 2010-2011, the application was tested by 136 students studying Graphic Expression modules, on their first year of an Industrial Engineering degree at the University of Burgos (Spain), specializing in mechanics, electronics and organization.

This ILMS_SVA took up three weeks of each course, with a total of 3 classroom hours for each taught class and individual student study time at home. The ILMS_SVA was used at the start of the course, with the aim of the improving visualization abilities that our students had learnt in their pre-university studies. The teacher explained how the ILMS_SVA functioned during the first half-hour, after which the students completed three sets of exercises in class. If they wish, students can also practice and create new sets of exercises or exams that are picked at random from the database.

At the end of the pilot project, a survey was conducted to evaluate the web-based application, over the two academic years, in order to:

- demonstrate whether the web-application was of sufficient quality to be used as a teaching tool;

- demonstrate that the contents of the web-based application had satisfactorily assisted our students in the development of their spatial visualization skills;

- and, observe the degree of satisfaction of the students that have used it.

Questionnaire design criteria proposed by various authors were followed for the preparation of the survey: Cea D'Ancona [40], Marzal [41], Martín Arribas [42], and Borges [43]. This 55-item survey (Annex 1), the responses to which were mainly on a 5-point Likert scale, had 4 parts: A) Internet experience; B) Technical difficulties experienced; C) Design, structure, and user friendliness of the web-based application; D) Assessment of the web-based application and its contents. A total of 96 students responded to the survey, giving a response rate of $70.6 \%$.

We used the SPSS statistical software program to assess the reliability indicators SPSS. As Cronbach's alpha is 0.87 , value higher than 0.7 , the internal consistency of the model is acceptable.

\section{Findings}

The mean average of the results for the items in blocks $\mathrm{C}$ and $\mathrm{D}$ of the questionnaire (Annex 1) are presented in the following table (Table 2), where the values between parentheses represent the standard error or standard deviation from the mean. The results of the items expressed in the negative were inverted.

The means of parts $\mathrm{C}$ and $\mathrm{D}$ of the survey are significatively greater than 3 at a confidence level of $95 \%$, after performing the student $t$ test on a sample using SPSS. 


\begin{tabular}{|c|c|c|c|c|c|}
\hline \multirow{2}{*}{\multicolumn{2}{|c|}{ Items }} & \multirow{2}{*}{$\begin{array}{l}\text { № pf } \\
\text { Items }\end{array}$} & \multirow{2}{*}{$\begin{array}{c}\text { Average } \\
\text { (std. error) }\end{array}$} & \multicolumn{2}{|c|}{ Confidence interval (95\%) } \\
\hline & & & & Lower & Upper \\
\hline \multicolumn{6}{|c|}{ C. Design, structure, facility of use } \\
\hline & Design and structure & 8 & $3.66(0.041)$ & 3.58 & 3,74 \\
\hline & Quality of resources & 4 & $3.70(0.057)$ & 3.59 & 3,81 \\
\hline & Utility of resources & 8 & $3.74(0.048)$ & 3.65 & 3,84 \\
\hline & Facility of use & 5 & $3.54(0.052)$ & 3.44 & 3,65 \\
\hline & Average & 25 & $3.67(0.037)$ & 3.59 & 3,74 \\
\hline \multicolumn{6}{|c|}{ D. Evaluation on contents } \\
\hline & Motivation and utility of contents & 8 & $3.93(0.051)$ & 3.82 & 4,03 \\
\hline & Appropriateness of contents & 7 & $3.67(0.045)$ & 3.58 & 3,76 \\
\hline & Average & 15 & $3.81(0.041)$ & 3.73 & 3,89 \\
\hline Item 52 & SVA has increased after using the application & 1 & $3.18(0.084)$ & & \\
\hline Item 53 & General evaluation of the application & 1 & $4.03(0.064)$ & & \\
\hline
\end{tabular}

We can draw a set of weak and strong points of the tool from an analysis of the average results of the survey:

\section{1: Strong points:}

- The use of the 3D viewer is useful from an educational point of view (4.3 points out of 5).

- The application is motivating, agreeable and knowing the solutions to the exercises assists study. The application, which needs no specific training, is motivating, because it encourages student participation in the learning process.

- The resources (3D viewer, images, video and audio files, etc.) are useful and satisfactory.

- The application is useful for teaching as a helpful complement to self-study and as an informative tool on learning progress.

2: Weak points needing improvement:

- Quality of videos and audio files. It is proposed to edit the videos again with new Codecs, highlighting the edges of the 3D models to improve their viewing quality.

- The 3D viewer eDrawings is complicated to operate; perhaps because it is the first time students have used a 3D viewer and because some students have had difficulties installing the viewer at home. Instructions on the operation of the viewer have been added to the help menu.

- Access to the help menus is neither rapid nor easy. More accessible links in better positions have been added to the help menus.

- The perception that the students have regarding improvements to their spatial skills owing to their use of the application. This may be because the exercises are not very difficult, as the application is designed more for students with greater visualization difficulties. We propose the inclusion of new exercises with a greater degree of difficulty. 
We may say on the basis of the results of block A of the survey that the great majority of our students have access to Internet at home (96\%), use Internet between 1 and 3 hours a day $(71 \%)$ and use Internet less than one hour a day for educational purposes $(70 \%)$.

On the basis of items 54 "Would you use this application again to improve your spatial visualization skills?" and 55 "Would you recommend this application to other people with an interest in the topic it covers?" of the survey results, we would highlight the positive answers of $89 \%$ and $98 \%$ of our students, respectively. Finally, it may be said that none of the survey items scored less than 3 out of 5 points.

\section{EXPERIMENTAL TRIALS}

The experimental trials involving ILMS_SVA were completed at the University of Burgos over the 2009-2010 and 2010-2011 academic years.

A quasi-experimental pre-test/post-test design was conducted. Two equivalent groups were formed by matching prior knowledge of SVA and Technical Drawing (TD): $1^{\circ}$ ) group E (students that only used IT_SVA in the classroom and in their homes, see figure 10); and $2^{\circ}$ ) group $\mathrm{T}$ (a control group of students that learnt SVA with a traditional pen-and-paper-based methodology). Initially, 270 students participated in the trial experiment (135 in group E), for which purpose 5 weeks in each year were set aside, 3 of which were for the completion of SVA test exercises. Students completed the Mental Rotation Test (MRT) [44] in the first week and repeated it in the last week of the experimental trial.

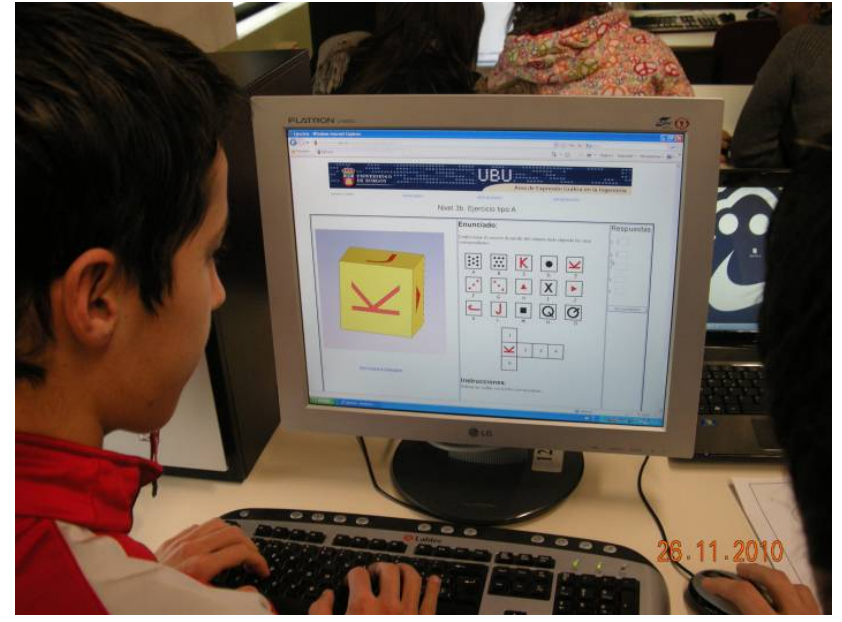

Fig. 10. Student completing a test exercise in ILMS SVA

The average results of both groups (E and $\mathrm{T})$ in the post-MRT test showed significant improvements $(\alpha<0.05)$ in visual ability, in comparison with the results of the pre-MRT test: students in groups $\mathrm{E}$ and $\mathrm{T}$ respectively finished 4.5 points and 3.5 points higher (Fig. 11). We should likewise affirm that, even though students using ILMS_SVA obtained better results for their SVA than students using the traditional methods, these results were not significant.

If we look at the results obtained in the Graphic Expression study modules of the Industrial

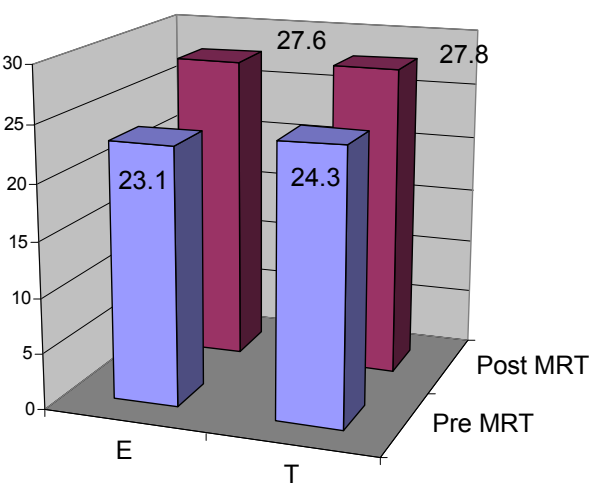

Fig. 11. Comparison of groups $\mathrm{E}$ and $\mathrm{T}$ in the MRT test

Engineering degrees, $36.7 \%$ of students had no prior knowledge of Technical Drawing (TD) when they arrived at the University of Burgos. As a consequence, the classes did not have similar levels of SVA, provoking imbalanced and uneven rates in the teaching/learning 
process. The study therefore went on to examine the influence of ILMS_SVA on students with and without prior knowledge of TD.

At the end of both academic years, all students completed the same exam, in which one section entitled "VISION" evaluated SVA competence. The students' results in the VISION section in both the control group $\mathrm{T}$ and the experimental group $\mathrm{E}$, were divided between the students with prior knowledge of TD and those with no prior knowledge of TD when they arrived at the University of Burgos.

\begin{tabular}{|c|c|c|c|}
\hline \multicolumn{3}{|c|}{ Table 3. Abbreviation of Variables } \\
\hline \hline \multirow{2}{|c|}{ Variables } & Traditional group (T) & Experimental group (E) \\
\hline \multirow{2}{*}{ "VISION" after experimentation } & Students with prior knowledge of TD & TTD & ETD \\
\cline { 2 - 4 } & Students with no prior knowledge of TD & TNTD & ENTD \\
\hline
\end{tabular}

Having defined the variable VISION on a 7- point scale, the average differences in the experimental group between students with and without prior knowledge of technical drawing were ETD-ENTD $=0.12$, as against the difference in the traditional group that was TTD-TNTD $=0.54$ (Fig. 12 and Table 3). Statistically, we can affirm to a level of significance of $\alpha<0.1$, that there are no significant average differences for SVA in the experimental group at the end of the course, between students with and without prior knowledge. However, these differences are found in the group $\mathrm{T}$ that used traditional teaching methods. Accordingly, our University recommends that students entering these engineering degree courses with no prior knowledge of TD should make use of ILMS_SVA.

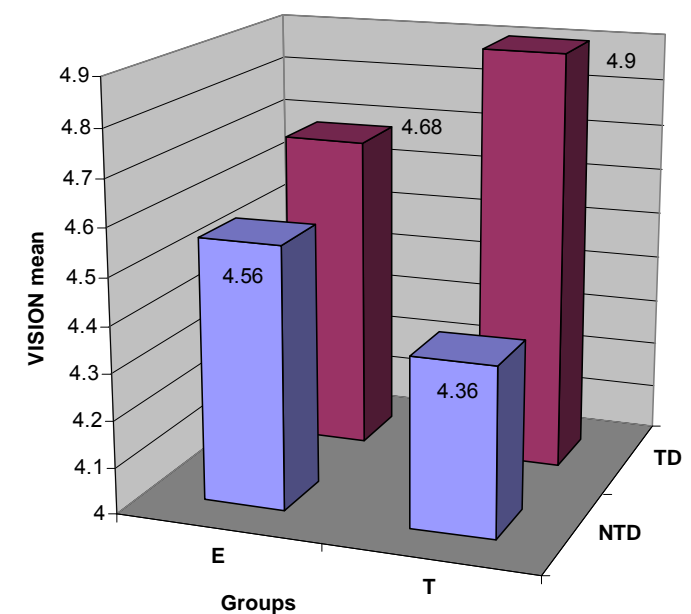

Fig. 12. Increased visualization skills for the variable VISION

\section{INNOVATIVE CONTRIBUTIONS AND CONCLUSIONS}

A new ILMS with educational content on SVA has been designed. The main features of this ILMS_SVA are that: 1) as an active and interactive methodological tool, it assists student learning of SVA on engineering graphics courses, on all engineering disciplines; 2) in each exercise, the student can manipulate the virtual 3D model on-screen; 3) it allows selfevaluation after each exercise, which the teacher can set or the student can access at random from the database; 4) it incorporates a pre-test to determine the level of prior knowledge, so that the ILMS_SVA can recommend a particular learning level to the student; 5) it is a tool for both teachers and students to track learning achievements.

Table 1 has listed the available open-source web-based tools for the development of SVA. The information in this table confirms that none of the applications comply with the 8 stated requirements except our application. The principal differences with some (but not all) of these applications is that the ILMS_SVA has 3D manipulable objects, calculates and displays the 
results and grades of the completed exercises, tracks learning through a database connection, and has been used and validated in a comparison.

According to our experiments with ILMS_SVA, the survey, and the comparison with table 1, our most important contributions are: the use of the 3D eDrawings viewer that helps the student to understand the cognitive process of mental rotations; students can take pre-tests to establish their level of SVA; ILMS_SVA offers more information to students and teachers on the evaluation results and follow up of learning achievements than the other tools that have been reviewed; and finally, ILMS_SVA is a valid and useful tool of sufficient and proven quality for managing this type of learning.

Taking into account the survey results we concluded that the ILMS needed to integrate a 3D viewer to help develop SVA. The manipulation of 3D models, by means of rotations, within $3 \mathrm{D}$ visualizers, helps students to understand the aforementioned cognitive process of spatial rotation.

It may be also concluded from the experimental trials that ILMS_SVA is a useful tool to improve SVA, and was even of greater effectiveness for those students that accessed engineering courses with no prior knowledge of TD.

In addition to this point, it helps teachers, as they can repeat this training in following years with new students, using up less preparation time and reducing the time spent correcting the various set exercises. They can also confirm the knowledge of their students by their rate of SVA learning. The teacher can immediately assess the strengths and weaknesses of the group of students by their level of SVA.

In summary, we can affirm that the combination of ILMS_SVA, the 3D viewers and the associated methodology, give students the opportunity to manipulate 3D models, to complete preliminary level assessment tests, to complete self-evaluation exercises, and finally, to provide tutors with a tool to track student-learning achievements.

\section{ACKNOWLEDGEMENTS}

The authors wish to thank Sara González Navarro and Miriam González Villafranca, students of Computer Management Engineering, for their help with computer programming, as well at the collaboration of their tutor Carlos Pardo Aguilar and all the students and teachers that helped us fine-tune the ILMS_SVA

\section{REFERENCES}

1. R. R. Hake, "Relationship of individual student normalized learning gains in mechanics with gender, high-school physics, and pretest scores on mathematics and spatial visualization", Physics Education Research Conference, on line http://www.physics.indiana.edu/ hake/PERC2002h-Hake.pdf, Boise, Idaho, 2002, p. 14.

2. S. Sorby, Spatial abilities and their relationship to effective learning of 3-d solid modeling software, Engineering Design Graphics Journal, 64 (2000), no. 3, 30-35.

3. C. L. Miller and G. R. Bertoline, Spatial visualization research and theories: Their importance in the development of an engineering and technical design graphics curriculum model, Engineering Design Graphics Journal 55 (1991), no. 3, 5-14. 
4. J. L. Saorín Pérez, R. Navarro Trujillo, N. Martín Dorta, J. Martín Gutiérrez and M. Contero, La capacidad espacial y su relación con la ingeniería [Spatial capacity and its relation to engineering], DYNA Ingeniería e Industria 84 (2009), no. 9, 721-732.

5. J. Martín-Gutiérrez, F.A. Gil, M. Contero, J.L. Saorín, Dynamic three-dimensional illustrator for teaching descriptive geometry and training visualisation skills. Computer Applications in Engineering Education 21 (2013) no. 1, 8-25.

6. J. M. Duff and H. B. Kellis, "ENVISIONS at red mountain high school", 63rd Annual ASEE/EDGD Mid-Year Conference Proceedings, on line http://edgd.asee.org/conferences/proceedings/63rdMid/papers/duff_monday.pdf, Berkeley, California, 2009.

7. C. Brus, L. Zhao and J. Jessop, "Visual-spatial ability in first-year engineering students: A useful retention variable?", Proceedings of the 2004 American Society for Engineering Education Annual Conference \& Exposition, American Society for Engineering Education, Salt Lake City, UT, 2004.

8. T. W. Knott and J. C. M. Kampe, "ENVISIONS at virginia tech", 63rd Annual ASEE/EDGD Mid-Year Conference Proceedings, on line http://edgd.asee.org/conferences/proceedings/63rdMid/papers/knott_monday.pdf, Berkeley, California, 2009.

9. R. B. Guay, "Purdue spatial visualization test: Rotations," Purdue Research Foundation, West Lafayette, IN, 1977.

10. S. A. Scribner and M. A. Anderson, Novice drafters' spatial visualization development: Influence of instructional methods and individual learning styles, Journal of Industrial Teacher Education 42 (2005), no. 2, 38-60.

11. B. Harper, J. G. Hedberg and R. Wright, Who benefits from virtuality?, Computers \& Education 34 (2000), 163-176.

12. "Web 3d consortium", vol. 2010, http://www.web3d.org/realtime-3d/, Mountain View, CA, 1999, pp. Open Standards for Real-Time 3D Communication. A nonprofit organization that develops and maintains the X3D, VRML, and H-Anim standards - 3D file formats and runtime specifications for the delivery and integration of interactive 3D data over networks: open, royalty-free and ISO-ratified.

13. M. G. Violante and E. Vezzetti, Implementing a new approach for the design of an elearning platform in engineering education, Computer Applications in Engineering Education Article in press (2012), on line http://dx.doi.org/10.1002/cae.21564.

14 L. Chittaro, R. Ranon, Web3D technologies in learning, education and training: Motivations, issues, opportunities. Computers \& Education 49 (2007) no. 1, 3-18.

15. S. Sorby, B. Baartmans, A course for the development of 3-D spatial visualization skills. Engineering Design Graphics Journal 60 (1996) no 1, 13-18.

16. A. Rafi, K. Anuar, A. Samad et al., Improving spatial ability using a Web-based Virtual Environment (WbVE). Automation in construction 14 (2005) no. 6, 707-715.

17. D. S. Koch, The Effects of Solid Modeling and Visualization on Technical Problem Solving. Doctoral thesis of the Virginia Polytechnic Institute (2006). http://scholar.lib.vt.edu/theses/available/etd-05192006-142531/unrestricted/KochDissertation.pdf (Jul. 2010)

18. E.I. Konukseven, Web-based education support tools used for teaching the "engineering Graphics" course, Key Engineering Materials 419-420 (2010), 777-780.

19. P. Pando Cerro, P. Alvarez Peñín, M. Perez Morales and A. Higuera Garrido, Research regarding the implementation of an interactive application for educational improvement of engineering drawing, Computer Applications in Engineering Education 19 (2011) no. 1, 183-192. 
20. T. M. C. Simões, J. J. P. C. Rodrigues and I. de la Torre, Personal learning environment box (PLEBOX): A new approach to e-learning platforms, Computer Applications in Engineering Education, Article in press (2011). on line http://dx.doi.org/10.1002/cae.20537.

21. C. Melgosa, B. Ramos, E. Baños and E. García, "Herramientas web para el desarrollo de la visión espacial y el seguimiento del aprendizaje [Web tools for the development of spatial vision and the follow up of learning]", Congreso Internacional Conjunto XXI INGEGRAF - XVII ADM, Lugo (Spain),2009,110-117.

22. J. Martín, N. Martín, J. L. Saorín, M. Contero and R. Navarro, "Aplicaciones web para el desarrollo de las habilidades espaciales [Web applications for the development of spatial abiliites]", XX Congreso Internacional de Ingeniería Gráfica, Ingegraf, Valencia (Spain), 2008, 266-274.

23. J. Martín Gutiérrez, "Estudio y evaluación de contenidos didácticos en el desarrollo de las habilidades espaciales en el ámbito de la ingeniería [Study and evaluation of the didactic contents in the development of spatial abilities in the field of engineering]", Departamento de INGENIERÍA GRÁFICA, vol. DPh, Universidad Politécnica de Valencia, Valencia (Spain), 2010, p. 762.

24. B. Ramos Barbero, E. García Maté, E. Baños García and C. Melgosa Pedrosa, "Aprendizaje innovador en la visualización de piezas y dispositivos, en la formación de dibujo técnico mediante aplicación hipermedia [Innovative learning in the visualization of pieces and mechanisms in the training of technical drawing with a hypermedia application]", XIII-ADM XV-INGEGRAF. International Conference on tools and methods evolution in engineering design, Cassino, Napoli y Salerno (Italy), 2003, 6-14.

25. M. Contero, F. Naya, P. Company, J. L. Saorín and J. Conesa, Improving visualization skills in engineering education, Computer Graphics in Education, IEEE 25 (2005), no. 5, 24-31.

26. D.G. Blasko, et al., VIZ: The visualization assessment and training Web site. Behavior Research Methods, Instruments, \& Computers 36 (2004), no. 2, 256-260.

27. S.W. Crown, Improving visualization skills of engineering graphics students using simple javascript web based games. Journal of Engineering Education 90 (2001) no. 3, 347-355.

28.E. Hart, et al., Using the internet to illuminate NCTM's principles and standards, Technology supported mathematics learning environments W. Masalski and P. Elliott (Editors), National Council of Teachers of Mathematics, Reston, VA, 2005.

29. P.E. Connolly and K.R. Maicher, The developing and testing of an interactive Web-based Tutorial for Ortographic Drawing instruction and Visualization Enhancement, American Society for Engineering Education (ASEE) Annual conference \& Exposition, Portland, OR: American Society for Engineering Education, 2005.

30. N. Martin-Dorta, J. L. Saorin and M. Contero, Web-based spatial training using handheld touch screen devices, Educational Technology \& Society 14 (2011), no. 3, 163-177.

31. R. J. Fang, S. F. Chao, and L. C. Weng, Study of 3D interactive model Web construction for vocational high school drawing courses in Taiwan. Advanced Learning Technologies ICALT, Fifth IEEE International Conference, 2005.

32. A. Guirao Sánchez, "Análisis comparativo de los programas oficiales de dibujo técnico en la enseñanza media y su implicación en las tecnologías de la información y de la comunicación (TIC) como recurso metodológico [Comparative analysis of official technical drawing curricula in secondary education and their use of Information and Communication Technology (ICT) as a methodological resource.]". Departamento de Dibujo - Departament de Dibuix, vol. DPh, Universitat Politècnica de València. Valencia (Spain). 2009, p 773. 
33. Hung, P.-H., Hwang, G.-J., Lee, Y.-H., Su, I.-H, A cognitive component analysis approach for developing game-based spatial learning tools, Computers and Education, 59 (2012) no.2, 762-773.

34. T. Pérez Carrión and M. Serrano Cardona, Ejercicios para el desarrollo de la percepción espacial [Exercises for the development of spatial perception], Editorial Club Universitario, Alicante (Spain), 1998.

35. S. Titus and E. Horsman, Characterizing and improving spatial visualization skills, Journal of Geoscience Education 57 (2009), no. 4, 242-254.

36. S. Sorby, Introduction to 3d spatial visualization: An active approach, Thomson Delmar Learning, Clifton Park, New York, 2003.

37. H. K. Ault and S. John, Assessing and enhancing visualization skills of engineering students in Africa: A comparative study, Engineering Design Graphics Journal 74 (2010), no. 2, 12-20.

38. N. L. Veurink, A. J. Hamlin, J. C. M. Kampe, S. A. Sorby, D. G. Blasko, K. A. HollidayDarr, J. D. Trich Kremer, L. V. Abe Harris, P. E. Connolly, M. A. Sadowski, K. S. Harris, C. P. Brus, L. N. Boyle, N. E. Study and T. W. Knott, Enhancing visualization skillsimproving options and success (ENVISIONS) of engineering and technology students, Engineering Design Graphics Journal 73 (2009), no. 2, 17.

39. N. Veurink, A. Hamlin and S. Sorby, "ENVISIONS incorporating spatial visualization curriculum across the United States", Conference on Research and Training in Spatial Intelligence, Chicago, Illinois, 2008.

http://www.ed.mtu.edu/spatial2008/presentations/veurink_and_Others.ppt

40. M. A. Cea D'Ancona, Metodología cuantitativa: Estrategias y técnicas de investigación social [Quantitative methodology: Social research strategies and techniques], Editorial Síntesis, Madrid, 1998.

41. M. A. Marzal, J. Calzada-Prado and M. Viannello, "Criterios para la evaluación de la usabilidad de los recursos educativos virtuales: Un análisis desde la alfabetización en información [Criteria for the evaluation of the usability of virtual educational resources: An analysis from the point of view of computer literacy]," Information Research 13 (2008), p. 387, available at http://InformationR.net/ir/13-4/paper387.html

42. M. C. Martín Arribas, Diseño y validación de cuestionarios [Design and validation of questionnaires], Matronas Profesión 5 (2004), no. 17, 23-29.

43. H. Borges de Barros Pereira, "Análisis experimental de los criterios de evaluación de usabilidad de aplicaciones multimedia en entornos de educación y formación a distancia [Experimental analysis of the evaluation criteria of the usability of multimedia applications in the field of distance education and training]," EXPRESSIÓ GRÀFICA A L'ENGINYERIA, vol. DPh, Universitat UPC (Politécnica de Cataluña), Barcelona (Spain), 2002 , p. 414.

44. S. G. Vanderberg and A. R. Kuse, Mental rotations, a group test of three-dimensional spatial visualization, Perceptual and Motor Skills 47 (1978), 599-604. 


\section{Annex 1}

\section{EVALUATION SURVEY OF THE WEB-BASED APPUCATION CALCUBU}

- The objective of this survey is a user assessment of the application "unw2.ubues/calcubu". - Please respond to the questions sincerely. Do not hesitate to consult the application again if you have any doubts or to be certain of your answer.

\section{Mark the chosen option with an $\mathbf{X}$}

\section{A Internet Experience}

Daily hours of Intemet use

Less than $1 \quad 1$ to $3 \quad 3$ to $5 \quad 5$ to 8 Mbre than 8

2 Daily hours of Intemet use for educational purposes

3 Do you have internet access at home?

$\begin{array}{ll}\square & \square \\ \text { YES } & \text { No } \\ \square & \square \\ \square & \square\end{array}$

4 If yes, have you used the application at home?

\section{B. Technical difficulties experienced (at home and in the classroom)}

5 Technical difficulties experienced (more than one option may be selected)

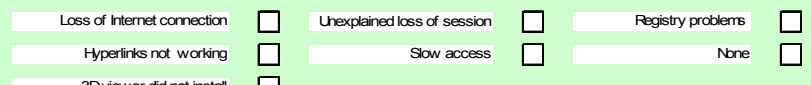

6 Weekly frequency of these difficulties

$$
\text { < unce 1-5 times 6-10 times >10 times }
$$

$$
\text { < 12 hours 12-24 hours 2-6 days >1 week Never }
$$

7 How long did it take to solve them?

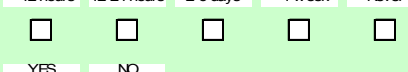

8 Have you had problems viewing the videos?

9 Have you had problems listering to the audio?

10 What software/plugins have you had to download (more than one option may be selected)?

$$
\text { Wndows media player } \square \quad \text { 3D viewer } \square \quad \text { internet Explorer } \square
$$

C. Design, structure, ease of use

Assess your degree of agreement with the features, quality and usefuness of the following aspects of the application. Place an $\mathbf{X}$ next to $\mathbf{1}$ if you strongly disagree, $\mathbf{2}$ if you disagree, $\mathbf{3}$ if you are indifferent, 4 if you agree, 5 if you strongly agree

11 Presentation and appearance of the screens, with regard to colors and backgrounds

12 Font type and size

13 Placement of navigation buttons

14 Relation of icons and buttons with their content or function (i.e.: a green icon indicates correct or the buttons do what they say they will)

15 Image quality

16 Quality of 3D objects

17 Video quality

18 Audio quality

19 On-screen distribution with regard to principal points, sub-points, areas of $3 \mathrm{D}$ objects, images and response zones

20 Usefuness of the images

21 Usefuness of text

22 Usefuness of 3D objects

23 Usefulness of videos

Signal your degree of agreement with the following affirmations. Place an X next to 1 if you strongly disagree, $\mathbf{2}$ if you disagree, $\mathbf{3}$ if you are indifferent, $\mathbf{4}$ if you agree, $\mathbf{5}$ if you strongly agree

24 The application features are attractive in general
25 The different used languages are successfully integrated (graphics, text, audio, etc.)

26 It is easy to know where you are at ary time in the application (orientation)

27 Information on the application is easy to access and go forward (navigation)

28 Operation of the 3D viewer is complicated

29 Access to instructions and the help menu is rapid and easy

30 This application is easy to use, i.e. needs no specific training

31 The application is usefu in teaching as a helpfu complement to self-study

32 The application is usefu in teaching as a tool that provides information on study progress

33 Other programmes and formats (pdf, flash, etc.) on theoretical subjects are needed

34 Instructions in the use of the 3D viewer are useful

35 The applicaiton presents unnecessary elements

\section{Assessment of the contents}

This application is motivating because it encourages my participation in the leaming process

37 The application presents information in a way that find agreeable and interesting

38 Knowing the quantitative results of the exercises appears motivating and helps me to study

39 I think that knowing the user statistics and cornection times is usefu

40 The clarity of the language used in the explanations for the videos and the problem statements is difficult

41 The 3D object viewer is useful in this application from the educational point of view

42 I think that the random compilation of exercises from the level that I choose is very usefu

43 The difficulty of the exercises is acceptable

44 The possibility of the teacher setting me exercises and exams appears very usefu

45 The resources empoyed (3D viewer, images, videos, $\quad \square \quad \square \quad \square \quad \square \quad \square \quad \square$ audios, etc.) are appropriate

46 The number of exercises is appropriate

47 The levels are appropriate appropriately calculated

49 There is contradictory content in this application $\quad \square \quad \square \quad \square \quad \square \quad \square \quad \square$

50 This application is useful for the subjetc "Graphic $\quad \square \quad \square \quad \square \quad \square \quad \square \quad \square$ Expression and Computer-Aided Design" Mark the chosen option with an $X$

Indicate frequency of use of the videos on theoretical $\square$ subjects and the examples

52 After using the application little Little Enough Alot A great des skills have increased:

53 Overall assessment of the application

54 Would you use this application again to improve your spatial visualization skills?

55 Would you recommend this application to other $\square \quad \square$ people with an interest in the topic it covers?

Obsenations: 